REVISTA DE DERECHO UNED, NÚM. 18, 2016

\title{
LA AUTONOMÍA LOCAL EN LA DOCTRINA Y EN LA JURISPRUDENCIA DEL TRIBUNAL CONSTITUCIONAL
}

\author{
LOCAL AUTONOMY IN DOCTRINE AND IN THE \\ JURISPRUDENCE OF THE CONSTITUTIONAL COURT
}

\author{
SANTIAgo García ARANDA \\ (Universidad Unir) \\ Doctor en Derecho
}

\begin{abstract}
Resumen: La Constitución Española de 1978 ofrece una escasa definición y contenido de la Autonomía local, no obstante, proporciona el marco para la configuración de este Principio General de la organización territorial del Estado. Así pues, van a ser la legislación de desarrollo, la jurisprudencia del Tribunal Constitucional y la doctrina científica quienes se ocuparán de esclarecer qué vamos a entender por autonomía de los entes locales para la gestión de sus intereses. En el presente trabajo nos centramos en el papel que han jugado y juegan, tanto la doctrina como la jurisprudencia del Tribunal Constitucional, en la configuración de esta institución jurídica, tratando de señalar las limitaciones dadas por su actual regulación en nuestra Carta Magna así como determinadas propuestas ante una eventual reforma constitucional.
\end{abstract}

Abstract: The Spanish Constitution of 1978 offers little definition and content of local autonomy, however, provides the framework for the setting of this General Principle of the territorial organization of the state. So will be the implementing legislation, the jurisprudence of the Constitutional Court and the Constitutional theory who will address clarify what we mean by autonomy of local authorities to manage their interests. In this paper we focus on the role they have played and play, both the doctrine and the jurisprudence of the Constitutional 
Court, in the configuration of this legal institution, trying to point out the limitations given by its current regulation in our Constitution as well as certain proposals to a possible constitutional reform.

Palabras clave: Autonomía local, jurisprudencia constitucional, doctrina constitucional, reforma constitucional, Tribunal Constitucional.

Keywords: Local Autonomy, constitutional jurisprudence, constitutional theory, constitutional reform, Constitutional Court.

Recepción original: 05/01/2016

Aceptación original: 6/04/2016

Sumario: 1. Introducción. 2. Una Autonomía administrativa según la Jurisprudencia del Tribunal Constitucional. 3. La Doctrina ante la Jurisprudencia de la Autonomía administrativa. 4. El carácter bifronte del régimen local según la Jurisprudencia del Tribunal Constitucional. 5. La Doctrina ante el carácter bifronte del régimen jurídico de la Administración local. 6. La técnica de la garantía institucional en la Jurisprudencia del Tribunal Constitucional. 7. La Doctrina ante la técnica de la garantía institucional. 8. La Jurisprudencia del Tribunal Constitucional y la Doctrina ante la Autonomía local: Conclusiones.

\section{INTRODUCCIÓN}

La Autonomía local en nuestro constitucionalismo, tal y como se ha puesto de manifiesto con anterioridad ${ }^{1}$, ha sido un principio vivo que se ha ido configurando a lo largo de los dos últimos siglos, llegándose a su proclamación, en nuestro vigente Texto constitucional, como Principio General para el ejercicio de la fundamental función que se atribuye a los entes locales como estructura básica de la organización territorial del Estado.

La Constitución Española de 1978, sin separarse de la tradición histórica de nuestro constitucionalismo en lo escaso de los preceptos dedicados a los entes locales, nos ofrece el marco para la configuración actual de la Autonomía local. Y es un marco definido, en buena medida, por el epígrafe del capítulo segundo del Título VIII, «De la Administración local», que ha tenido consecuencias determinantes para conformar el grado y alcance de la autonomía de nuestros entes

${ }^{1}$ GARCÍA ARANDA, S., La Autonomía Local en España (1808-1978). Ed. Universitas, Madrid, 2013. 
locales. Por otro lado, hay que señalar la escasa definición y contenido que expresamente recoge el vigente Texto constitucional de este fundamental Principio General de la organización territorial del Estado, por lo que serán la legislación de desarrollo, la jurisprudencia y la doctrina a quienes va a corresponder dar cuerpo a lo que vamos a acabar entendiendo por Autonomía local. Pues, en ningún momento, nuestra Carta Magna emplea tal expresión; reconociéndose y proclamándose, concretamente a municipios y provincias, la garantía constitucional de la autonomía de los municipios y la encomienda del gobierno y la administración autónoma, a las Diputaciones u otras corporaciones de carácter representativo.

En el presente trabajo procederemos al estudio de la Jurisprudencia y la doctrina, en su contribución a la configuración de la autonomía local. Para lo cual, seguiremos tres líneas, o mejor, tres ejes fundamentales: el de la consideración de la autonomía local como administrativa, tal cual la afirma el Tribunal Constitucional, o como política, hacia donde ha ido basculando, paulatinamente, de modo cada vez más mayoritario la doctrina iuspublicista española; el denominado por el Tribunal Constitucional carácter bifronte del régimen local, que algún sector de la doctrina cuestiona por entender que el Tribunal persiguió justificar una intervención estatal más allá de lo estrictamente básico según el artículo 149.1.18. ${ }^{a}$ de la Carta Magna, concediéndose al legislador estatal una etiqueta de garante de la autonomía local; y, en tercer lugar, la adopción por el Tribunal Constitucional de la técnica de la garantía institucional siguiendo a la doctrina administrativista, frente a otras propuestas de otra parte de la doctrina en la línea de una garantía constitucional que pretende ir más allá del carácter defensivo a que se limita la primera. En cualquier caso, se ha concluido que la "creación», al tratar de definir nuestro Principio General, o «recreación» para extraer el contenido constitucional de la Autonomía local -por utilizar términos del profesor GARCÍA FERNÁNDEZ- efectuada por la mayoría de la doctrina se ha quedado, únicamente, en los artículos correspondientes del Título II del Capítulo VIII de la Carta Magna, reduciéndose por tanto y limitándose notablemente lo que quizás pudo ser su concepción originaria. Todo ello, a la vista de su formulación para el cumplimiento de los fines encomendados a este básico nivel territorial de gobierno y administración, en un Estado social (de bienestar) como el proclamado por la Constitución Española de 1978.

Por otra parte, tal y como señala VELASCO CABALLERO, ese nivel de poder local que entendemos por «autonomía» resulta de un conjunto heterogéneo de normas jurídicas: de la Constitución, de los 
Estatutos de Autonomía, de las Leyes estatales y autonómicas, y de los Tratados internacionales ${ }^{2}$; de modo que para llevar a cabo un estudio de la Autonomía local, que incluya su configuración actual, no puede bastar con atender al diseño, funciones y regulación que, de los entes locales y su autonomía, hacen nuestro texto constitucional vigente y, por haberlo así previsto el constituyente, el legislador ordinario. Es imprescindible, por tanto, indagar y analizar cómo ha ido dotando de contenido a dicho Principio General la jurisprudencia del Tribunal Constitucional, intérprete supremo de la Constitución, así como observar las aportaciones de la doctrina tanto administrativista como constitucionalista, unas veces orientando y reforzando las posiciones del Constitucional, otras yendo más allá tras ponerlas en cuestión, y, en ocasiones, llegando a la más abierta contradicción. Se analizará, como se ha indicado, el papel de la doctrina científica y la jurisprudencia constitucional examinando los tres ejes señalados con objeto de observar el modo en que, en palabras de GARCÍA FERNÁNDEZ ${ }^{3}$, el Derecho constitucional realiza su tarea primordial de inferir de la Carta Magna una formulación completa del principio de Autonomía local en la medida que este principio ha de ser el instrumento que debe posibilitar la gestión de los intereses encomendados a estas entidades.

Con el nuevo Régimen Local de la Constitución de 1978, y como consecuencia del desarrollo normativo que a su amparo el legislador ha llevado a cabo, han sido numerosas las sentencias del Tribunal Constitucional sobre la materia. Y, como es sabido, la tarea que efectúa el Tribunal Constitucional al dictar sentencias es explicar el sentido de las normas jurídicas, especialmente de la Constitución, con el objeto de cubrir lagunas y crear seguridad jurídica, siempre sometido a los principios que constituyen los límites a la actividad interpretadora de la Norma Fundamental ${ }^{4}$. Por otra parte, no hay que olvidar que, hoy en día, la doctrina coincide en el carácter de fuente de la jurisprudencia constitucional ${ }^{5}$, por lo que más allá de las diversas posturas acerca del lugar que como tal ha de ocupar, correspon-

${ }^{2}$ VELASCO CABALLERO, F., «Autonomía municipal» ponencia del II Congreso de la Asociación Española de Profesores de Derecho Administrativo, Santander, 2 de febrero de 2007. Pág. 1.

${ }^{3}$ GARCÍA FERNÁNDEZ, J., "Derecho constitucional y entidades locales. Sistema de Fuentes y Autonomía como fundamentos constitucionales básicos del Derecho Local» en Parlamento y Constitución. Anuario N. ${ }^{\circ}$ 6, 2002. Pág. 228.

${ }^{4}$ GOIG MARTÍNEZ, J. M., NÚÑ̃Z RIVERO, C., NÚÑEZ MARTÍNEZ, M., La Constitución Española en la Jurisprudencia del Tribunal Constitucional. Vol. I, Ed. Universitas, Madrid, 2010, pág. 40.

${ }^{5}$ Op. cit., pág. 51. 
de, en adelante, atender a cómo nuestro intérprete supremo ha contribuido a la configuración de la Autonomía Local en el sistema político-institucional vigente.

En la jurisprudencia constitucional se pueden observar, además, dos periodos claramente diferenciados, la década de los 80' en la que encontramos una jurisprudencia tendente a originar una conceptuación de la Autonomía Local (con sentencias como la 4/1981 y la definición de la autonomía local como administrativa, o la 32/1981 con la adopción de la doctrina de la garantía institucional, o la 84/1982 en la que se señaló el carácter bifronte del régimen jurídico de las autonomía locales, o la 27/1987, o la 213/1988, o la 214/1989, etc.) y, otro periodo a partir de los años 90` donde el Tribunal Constitucional estableció los criterios de interpretación para configurar el principio de suficiencia financiera de los entes locales de nuestro artículo 142 de la Constitución (con sentencias como la 96/1990 donde se establece la suficiencia de recursos y no la autonomía financiera para las haciendas locales, o la 331/1992 y la suficiencia de medios para posibilitar la efectiva autonomía constitucionalmente garantizada, o la 171/1996 en idéntica línea, o la 109/1998 estableciendo la necesidad de eliminar condicionamientos indebidos y la plena disponibilidad de los ingresos de las haciendas locales para ejercer las competencias propias, o la 233/1999 que señala al Estado como legislador competente en exclusiva para hacer efectivo el principio de suficiencia financiera, sin perjuicio de la contribución en recursos de las Comunidades Autónomas, o la 104/2000 abundando en dicha postura, etc.).

Como se ha señalado, no pretende ser este un análisis exhaustivo de la evolución jurisprudencial sobre el objeto de nuestra investigación, sino más bien un estudio de la jurisprudencia fundamental en materia de régimen local con la finalidad de observar y analizar cómo ha contribuido la jurisprudencia del Tribunal Constitucional a la configuración de la Autonomía Local en nuestra España de la Constitución de 1978.

Y todo ello, a la espera de la Sentencia que el Tribunal Constitucional ha de dictar con respecto al Conflicto en defensa de la autonomía local contra determinados preceptos de la Ley 27/2013, de 27 de diciembre, de racionalización y sostenibilidad de la Administración local, cuando quizás se abra la posibilidad de encontrar alguna novedad en la jurisprudencia constitucional futura sobre nuestra materia, porque, como pondremos de manifiesto, existen nuevas propuestas de hermenéutica constitucional para avanzar en la configuración de este Principio General, dentro del marco de nuestra vigente Carta Magna. 


\section{UNA AUTONOMÍA ADMINISTRATIVA SEGÚN LA JURISPRUDENCIA DEL TRIBUNAL CONSTITUCIONAL}

El carácter administrativo, tal y como lo afirmó nuestro Tribunal Constitucional en sus Sentencias 4/81, 25/81 y 32/1981, de la Autonomía local ha sido y sigue siendo, objeto de discusión por parte de la doctrina $^{6}$. Hay una corriente doctrinal, afirman algunos autores que es una corriente amplia ${ }^{7}$, que sostiene, siguiendo la estela de la jurisprudencia del Constitucional, que el carácter administrativo de la autonomía local es el fundamental rasgo diferenciador de la misma, frente al carácter político de la autonomía de las Comunidades Autónomas. Señala la STC 32/1981, despejando toda duda acerca de su interpretación de la autonomía en Comunidades Autónomas y entes locales en la Constitución, que «La Constitución prefigura [...] entidades de distinto nivel, que son fundamentalmente el Estado y las Comunidades Autónomas, caracterizadas por su autonomía política, y las provincias y municipios, dotados de autonomía administrativa de distinto ámbito».

Efectivamente, la autonomía reconocida por la Constitución a las nacionalidades y regiones como «derecho» de éstas en el artículo 2 no se corresponde, en términos idénticos, con la que se señala "para la gestión de sus respectivos intereses» atribuyéndose por igual a municipios, provincias y Comunidades Autónomas, en el artículo 137.

Y, del mismo modo, no se configuran en términos de exacta correspondencia la autonomía de que gozan los entes regionales autónomos con un ámbito notablemente delimitado en el capítulo tercero

${ }^{6}$ No obstante, también se encuentran autores que consideran, en cierta medida, como algo simplista la definición de la autonomía local, bien como administrativa, bien como política. Es el caso de REQUEJO RODRÍGUEZ, P. en «El nuevo diseño de las competencias locales», en Cuadernos de Derecho Local n. ${ }^{\circ}$ 13, Febrero de 2007. Fundación Democracia y Gobierno Local.

${ }^{7}$ A lo largo del estudio se observará que, si bien es cierto que hay autores que sostienen el carácter administrativo como rasgo diferenciador de la autonomía local, no lo son en tan gran número como pudiera parecer en una primera impresión (encontramos en esta postura a Manuel ARAGÓN que sí le concede «relevancia política», o a Luciano PAREJO, aunque cada vez con más inclinación hacia un cierto carácter político). Y, por el contrario, son bastante más numerosos los que se inclinan por una consideración también, aunque sea parcialmente, política de la autonomía de los entes locales (entre otros, Francisco SOSA, Joaquín GARCÍA MORILLO, Javier GARCÍA ROCA, José Luis CARRO FERNÁNDEZ-VALMAYOR, Francisco CAAMAÑO, Mayte SALVADOR, etc.) o, al menos, por excluir lo administrativo y/o político como rasgos mutuamente excluyentes en la diferenciación de la autonomía local de la regional. 
del Título VIII de la constitución ${ }^{8}$ y, por otro lado, nuestros entes locales, sin ámbito constitucionalmente detallado y con sus facultades limitadas por la necesaria dependencia del legislador correspondiente. Las Comunidades Autónomas saben cuántas y cuáles son las competencias que pueden ejercer como propias desde la entrada en vigor de sus Estatutos, mientras que municipios y provincias necesitan que el legislador estatal y/o autonómico, según corresponda, vayan estableciendo sectorialmente cual es el alcance de la autonomía de estos entes locales, en función de cómo se vean afectados los intereses correspondientes ${ }^{9}$.

\section{3, LA DOCTRINA ANTE LA JURISPRUDENCIA DE LA AUTONOMÍA ADMINISTRATIVA}

Es indiscutible, la autonomía local no comporta la capacidad legislativa mientras la regional goza de ella dentro del marco definido por el bloque de la constitucionalidad. Pero de ahí a afirmar que una y otra autonomías se caracterizan por ser -en términos del Tribunal Constitucional- política, para nacionalidades y regiones, y administrativa, la local, supone abrir la puerta a posiciones doctrinales de carácter claramente discrepante que veremos a continuación (en adelante, y para simplificar, hablaremos de autonomía regional para referirnos a la primera, frente a la administrativa como pretendidamente caracterizadora de la autonomía local) ${ }^{10}$.

Así, encontramos al hoy desaparecido profesor GARCÍA MORILLO que afirmaba que con la aparición, en la Constitución de 1978, de unos órganos dotados de una fuerte autonomía política constitu-

${ }^{8}$ Y junto a él, lógicamente, el correspondiente Estatuto de Autonomía como norma institucional básica de cada Comunidad Autónoma y vía de acceso a la autonomía, mientras que, como se añade, en el caso de la autonomía local, ésta se llevará a efecto a través de la legislación estatal y/o autonómica.

${ }^{9}$ Así lo afirma primeramente la STC 32/1981 cuando subraya que «a diferencia de lo que ocurre con las instituciones supremas del Estado, cuya regulación orgánica se hace en el propio texto constitucional, en estas (Administraciones Locales) la configuración institucional concreta se difiere al legislador ordinario...»y, más tarde, con claridad meridiana la STC 214/1989 estableció que «la concreción última de las competencias locales queda remitida -y no podía ser de otra manera- a la correspondiente legislación sectorial, ya sea estatal o autonómica, según el sistema constitucional de distribución de competencias entre el Estado y las Comunidades Autónomas».

${ }^{10}$ En efecto, la Constitución Española de 1978 en su artículo 2 «reconoce y garantiza el derecho a la autonomía de las nacionalidades y regiones» y, por ello, cuando nos sirvamos de la expresión "autonomía regional», para referirnos a la caracterizada por el Tribunal Constitucional como política, para su contraposición a la local, entendida como administrativa, lo haremos solamente por razones de orden clasificatorio. 
cionalmente garantizada, las Comunidades Autónomas, se ha producido, como consecuencia, una intensificación de la administrativización de los entes locales. En su obra sobre la configuración constitucional de la autonomía local, hace hincapié en lo complicado de la distinción entre lo político y lo administrativo y señala que esa diferenciación ha venido dada, y se ha apoyado, en la jurisprudencia del Tribunal Constitucional pero que esa conceptuación de la autonomía local como puramente administrativa hay que relativizarla ya que cuando la propia Constitución -indicará Joaquín GARCÍA MORILLOotorga repetidamente autonomía a una institución, cuando define, con la incertidumbre que se quiera, su marco de actuación y, sobre todo, cuando sujeta el procedimiento de designación de sus órganos a lo politico por excelencia, que es la elección por sufragio universal libre, directo y secreto, la negación del carácter político es harto complicada ${ }^{11}$. Y se sirve de las referencias al modelo de democracia local y al funcionamiento democrático de los órganos de gobierno de las corporaciones locales como características esenciales del modelo constitucional de autonomía local, que hace el propio alto intérprete en la STC 33/1993, de 1 de febrero, para recordarnos que no cabe una definición más nítida del carácter político de la autonomía local.

Llegando aún más allá que GARCÍA MORILLO, el profesor Javier GARCÍA ROCA defiende la caracterización como política de la autonomía de los entes locales y afirma, en términos absolutos, que el principio democrático representativo produce una transformación en la naturaleza de la autonomía de los entes locales al entender que un municipio democrático nunca puede ser privado de su carácter político en lo que a su autonomía se refiere ${ }^{12}$. Señala GARCÍA ROCA, seguidamente, que la autonomía local no sólo es gestión administrativa de servicios, es también: dirección política propia, potestad normativa primaria, competencias definidas y atinentes al interés local, autonomía financiera, funcionarial, un Gobierno representativo de los vecinos que encabeza la Administración local, y responsabilidad política ante el electorado. Y, por otro lado, llama la atención sobre la desaparición de las viejas potestades gubernativas de suspender actos y acuerdos de las Corporaciones locales (con la excepción prevista en el art. 67 de la LRBRL) como un argumento más a favor de una autonomía política para los entes locales, ya que desaparecen los controles de oportuni-

${ }^{11}$ GARCIA MORILLO, J. La Configuración Constitucional de la autonomía local. Marcial Pons-Diputació de Barcelona, Madrid-Barcelona, 1998. Págs. 27 y 28.

12 GARCÍA ROCA, J. El concepto actual de autonomía local en LÓPEZ GUERRA, L. (Coord.) Estudios de Derecho Constitucional. Homenaje al Profesor Dr. D. Joaquín García Morillo, Tirant lo Blanch, Valencia, 2001. Pág. 669. 
dad política, quedando como vía de control, con carácter general, únicamente la jurisdiccional de la administración de justicia ${ }^{13}$. Añade por último, y desde un punto de vista teórico, el argumento acerca de cómo KELSEN en su Teoría General del Estado caracterizó la potestad normativa local como verdaderas normas generales y primarias aunque no se les llame «leyes» ${ }^{14}$. Y se apoya, finalmente, en la Carta Europea de Autonomía Local cuando ésta, en su preámbulo, señala que las entidades locales son uno de los principios fundamentales de un régimen democrático.

Por su parte, José Luis CARRO FERNÁNDEZ-VALMAYOR se apoya en la teorización general sobre el concepto de autonomía, que encuentra buena parte de su base en la doctrina italiana, para resaltar la importancia que tiene el aspecto político dentro del concepto de Autonomía local. Y toma de Giannini la caracterización de esta autonomía como política, entendida como la capacidad del ente autónomo de orientar y dirigir, politica y administrativamente la comunidad subyacente, ${ }^{15}$ afirmando que no se puede negar a los entes locales una potestad de orientación político-administrativa que no tiene su origen en el Estado sino en la mayoría política de la propia comunidad. Para este catedrático de Derecho Administrativo de Compostela, no se estaría ante diferencias de naturaleza, sino más bien de alcance o de grado de una y otra autonomías (local y regional).

El profesor Francisco CAAMAÑO DOMÍNGUEZ, por su parte, señala que la consideración de la autonomía local como administrativa, y no política, tiene su origen en que la autonomía de los entes locales en la España de la Constitución del 1978 comenzó a escribirse en negativo, señalándose por la doctrina y, sobre todo, por la jurisprudencia no tanto lo que era, sino aquello que no debería ser. Así, esta autonomía se definió como "no política» en la STC 4/1981, o en la 32/1981, indicándose que aunque estaba en la Constitución, la autonomía no tenía específico contenido constitucional, tal y como se señaló en la STC 170/1989, y se llega a una situación tan contradictoria como la actual en la que, en democracia, resulta que los órganos de

${ }^{13}$ La STC 4/1981, de 2 de febrero literalmente señala que «el principio de autonomía es compatible con la existencia de un control de legalidad sobre el ejercicio de las competencias, si bien entendemos que no se ajusta a tal principio la previsión de controles genéricos e indeterminados que sitúen a las Entidades locales en una posición de subordinación o dependencia casi jerárquica de la Administración del Estado y otras Entidades territoriales».

${ }^{14}$ GARCÍA ROCA, J. El concepto actual de autonomía local... en LÓPEZ GUERRA, L. Estudios de Derecho Constitucional. Homenaje al Profesor... op. cit., pág. 678.

${ }^{15}$ Se estaría refiriendo a la potestad de indirizzo politico-amministrativo de Massimo Severo GIANNINI, Diritto Amministrativo, vol. I, Giuffré, Milano, 1970. 
autogobierno más próximos al ciudadano resultan ser simples administraciones públicas de naturaleza corporativa. En una posición similar encontramos a José María SOUVIRÓN MORENILLA, quien señala que mientras la autonomía de las Comunidades Autónomas ha sido efectivamente reconocida, incluso en términos impensables cuando se promulgó la Constitución, la autonomía local consagrada también en nuestra Norma Fundamental no se ha desarrollado hasta llegar a considerar el gobierno local como un autogobierno efectivo, y ello a pesar de que en nuestros días la vida local ha asumido una progresiva importancia y constituye el gobierno más cercano a los problemas de los ciudadanos ${ }^{16}$.

Volviendo a CAAMAÑO, sostiene quien fuera Ministro de Justicia que la razón última de la consideración de la autonomía local como administrativa, frente a la política de las Comunidades Autónomas, no radica en la falta de carácter político de la autonomía local, sino en que la primera jurisprudencia del Tribunal Constitucional se elaboró, en la mayor parte de las ocasiones, no para pronunciarse acerca de la autonomía local, sino con la finalidad de reafirmar la de las Comunidades Autónomas, lo que argumentalmente se tradujo, a menudo, en un juego didáctico de contraposiciones: para subrayar que la autonomía de las Comunidades Autónomas era una genuina autonomía política y no un mero poder descentralizado subordinado al del Estado, se enfrentaba aquella autonomía a la local que se calificaba -para subrayar ese afán pedagógico- como meramente administrativa ${ }^{17}$. Considera el profesor CAAMAÑO que, hoy por hoy, solo el Tribunal Constitucional parece desconocer que la autonomía local es expresión de una verdadera autonomía política, y que los apoyos doctrinales que la concebían como simple autonomía administrativa ya son parte de la historia.

En el caso de Francisco SOSA WAGNER, la conceptuación de la autonomía local como meramente administrativa frente al carácter político de la autonomía de nacionalidades y regiones, así sin matizaciones, de una manera tan simplificadora -indica el profesor- resulta de una interpretación disconforme con la Constitución, refiriéndose

${ }^{16}$ SOUVIRÓN MORENILLA, J. M., Realidad y perspectivas de la organización territorial del Estado, Vol. II, Comares, Granada, 2000, pág. 145.

${ }^{17}$ CAAMAÑO DOMÍNGUEZ, F., Autonomía local y Constitución. Dos propuestas para otro viaje por el callejón del gato, Revista Española de Derecho Constitucional, Núm. 70, Enero-Abril 2004. Y también en Autonomía local, subsidiariedad y Constitución. Ministerio de la Presidencia. Madrid, 2004. En estos trabajos hace el Profesor Caamaño un ejercicio de interesante interpretación del intérprete. 
al artículo 140 sobre todo, tanto en su letra ${ }^{18}$, como en su espíritu ${ }^{19}$. Concluye que sin desconocer ni minusvalorar el distinto grado de la autonomía local y de la autonomía comunitaria, hay que convenir que aquélla no puede quedar reducida al componente administrativo, de la misma forma que ésta tampoco queda reducida al componente políti$\mathrm{CO}^{20}$. Y en esta misma línea cabría incluir el argumento de que la Carta Magna no recoge literalmente la expresión Autonomía Local, sino que proclama la autonomía de los «municipios, provincias y Comunidades Autónomas» pudiéndose entender que lo sea en distinto grado sin, necesariamente, serlo de distinta naturaleza.

En la postura doctrinal que defiende la naturaleza política de la Autonomía local encontramos sin ambages al profesor GARCÍA FERNÁNDEZ, quien opone a los defensores del carácter administrativo de la Autonomía el hecho de que siendo los entes locales administración, no son sólo administraciones y recurre a la propia Constitución cuando proclama que la Administración Pública no gobierna, es un instrumento separado del Gobierno que la dirige para la implantación de programas políticos de gobierno sometidos a la aceptación de los representantes del pueblo, democráticamente elegidos, que controlan la acción del gobierno en la dialéctica política gobierno-oposición. Y, parece evidente que los órganos de gobierno de los entes locales no realizan una gestión despolitizada, meramente burocrática y sin capacidad de dirección política. De hecho es por ello que, en sus propias palabras, «la doctrina más lúcida» habla de sistema político local ${ }^{21}$.

Por último, la profesora SALVADOR CRESPO entiende que disponer de la potestad legislativa es un criterio insuficiente para la caracterización de una autonomía como política, o en sus palabras para determinar el concepto de autonomía política ${ }^{22}$. Considera, en una línea basada en M. S. GIANNINI, que al resultar investidas de legitimidad

${ }^{18}$ Ciertamente, y además lo manifiesta SOSA WAGNER, cuando la Constitución habla de autonomía en el artículo 140, se refiere al gobierno y administración de los municipios, pero ya se ha señalado anteriormente que, por otra parte, el capítulo II que inaugura dicho artículo lo hace bajo el epígrafe «De la Administración local».

${ }^{19}$ Menos discutible es el argumento referido al espíritu, ya que la composición mediante sufragio universal, libre, igual, directo y secreto que establece el mismo artículo 140 da un carácter representativo democrático y, por tanto, político más difícil de cuestionar.

${ }^{20}$ SOSA WAGNER, F., Los principios del régimen local, en MUÑOZ MACHADO, S. (dir.) Tratado de Derecho Municipal, tomo I, 2. ${ }^{\mathrm{a}}$ ed., Civitas, Madrid, 2003. Pág. 164.

${ }^{21}$ GARCÍA FERNÁNDEZ, J., «Derecho constitucional y entidades locales. Sistema de...». Op. cit., pág. 227.

${ }^{22}$ SALVADOR CRESPO, M., La autonomía provincial en el sistema constitucional español. Intermunicipalidad y Estado autonómico, Fundación Democracia y Gobierno Local, Madrid, 2007. Pág. 66. 
democrática, las entidades locales tienen capacidad para imprimir a su labor una orientación política propia. Y, justamente, apoyándose en la función político-constitucional de la autonomía local de Luciano PAREJO, recuerda la importancia de la participación democrática de los ciudadanos en los asuntos públicos, singularmente en la valoración que se efectuaría en cada proceso electoral de la defensa de los intereses locales. Coincide con CAAMAÑ̃ en la crítica a la utilización de la consideración de la naturaleza de la autonomía de los entes locales para la reafirmación del alcance de la autonomía de las Comunidades Autónomas y, en el proceso inverso, de cómo ello ha afectado a la hora de definir la autonomía local.

A la vista de las argumentaciones de los distintos autores acerca de la naturaleza de la Autonomía local podría concluirse que, efectivamente, la carencia de la capacidad legislativa o el encabezamiento «De la Administración local» del capítulo que la Constitución le dedica resultan razones y argumentos insuficientes para negar el componente político indudable de la Autonomía local. Se ha observado cómo la doctrina iuspublicista española se inclina, de modo muy mayoritario, por la atribución de un carácter político a la Autonomía local. Otra cuestión será la consideración de la jurisprudencia constitucional sobre ese carácter administrativo en una visión e interpretación de tipo sistemático de la posición de los entes locales, y por tanto de la Autonomía local, que va a reservar y garantizar una posición de preeminencia del legislador estatal en la pugna competencial con las Comunidades Autónomas. Habrá, por tanto, que poner en relación esa naturaleza administrativa que se pretendió atribuir a la Autonomía local con otras interpretaciones constitucionales como la que incluyó la expresión régimen bifronte ${ }^{23}$.

\section{EL CARÁCTER BIFRONTE DEL RÉGIMEN LOCAL SEGÚN LA JURISPRUDENCIA DEL TRIBUNAL CONSTITUCIONAL}

El denominado por el Tribunal Constitucional carácter bifronte del régimen local hace referencia a su afirmación, en la Sentencia 84/1982, de 23 de diciembre ${ }^{24}$, de la doble dependencia legislativa de los entes

${ }^{23}$ STC 84/1982, de 23 de diciembre.

${ }^{24}$ Como se indicó anteriormente, la delimitación de competencias en materia local entre el Estado y las Comunidades Autónomas dará lugar a buena parte de la jurisprudencia que, en su función de enjuiciar la constitucionalidad de las leyes (en este caso, que afectan a las competencias sobre régimen local), ha contribuido a la configuración en nuestro derecho del alcance de la Autonomía local. Y, en esta línea, la mencionada STC 84/1982 tuvo su origen en un recurso de inconstitucionalidad 
locales en nuestra Constitución. De modo tal que la regulación sobre el régimen local, al no ser una materia exclusivamente estatal (aunque, como se ha señalado, sí sus bases según el artículo 149.1.18. ${ }^{\text {a) }}$ ni tampoco, lógicamente, de exclusivo ámbito autonómico (aunque se podrán asumir competencias en la materia, según el artículo 148.1.2. ${ }^{\mathrm{a}}$ ), resulta doblemente sometido a la legislación del Estado y de las Comunidades Autónomas, cada uno en el ámbito de sus competencias ${ }^{25}$. Así lo estableció la Sentencia mencionada en los términos siguientes: "Este carácter bifronte del régimen jurídico de las autonomías locales en algunas comunidades autónomas, que hace imposible calificarlo de forma unívoca como 'intracomunitario' o 'extracomunitario', no es contradictorio con la naturaleza que a las entidades locales atribuye la Constitución, cuyo artículo 137 concibe a municipios y a provincias como elementos de división y organización del territorio del Estado. Dividido y organizado, también éste en su integridad y sin mengua de ella, en comunidades autónomas, ambas normas de organización se superponen sin anularse $[\ldots] »$.

Régimen bifronte que, en la consideración de los entes locales desde una perspectiva constitucional de administración pública, dará pie al Estado para, apoyándose en el título competencial del

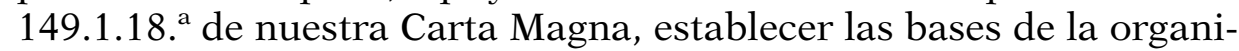
zación y la estructura local, o como señala el propio precepto, «Las bases del régimen jurídico de las Administraciones públicas y del régimen estatutario de sus funcionarios que, en todo caso, garantizarán a los administrados un tratamiento común ante ellas; el procedimiento administrativo común $[\ldots]{ }^{26}$.

interpuesto por la Generalitat de Cataluña, contra el artículo 28 de la Ley de Presupuestos Generales del Estado para 1982, que facultaba al Gobierno de la nación para, en su caso, llevar a cabo transferencias o delegaciones de atribuciones y funciones a las entidades locales.

${ }^{25}$ Luciano PAREJO, en unos términos que aportan gran claridad, vendrá a afirmar que al no "pertenecer», para ultimar el régimen local, la Administración local a ninguna de las instancias con capacidad legislativa (Estado y Comunidades Autónomas) «pertenece», al mismo tiempo, a las dos y, éstas, «están vinculadas a la 'predeterminación' constitucional y sólo pueden desarrollarla (en lo básico primero y en la particularización de lo básico de acuerdo con las características de cada Comunidad Autónoma luego) para la compleción de la definición del Estado en su totalidad. La doctrina del Tribunal Constitucional sobre el carácter 'bifronte' de la Administración local debe entenderse justamente en tales términos». PAREJO ALFONSO, L., La Garantía Institucional: crítica y verdadera operatividad de esta técnica, en La configuración constitucional de la autonomía local, GARCÍA MORILLO, J., Marcial Pons-Diputació de Barcelona, Madrid-Barcelona, 1998. Pág. 61.

${ }^{26}$ En nuestra opinión, la consideración de la Autonomía local como meramente administrativa que efectúa el Tribunal Constitucional formaría parte de una sistemática interpretativa más amplia en la que, además de otras interpretaciones que pue- 


\section{LA DOCTRINA ANTE EL CARÁCTER BIFRONTE DEL RÉGIMEN JURÍDICO DE LA ADMINISTRACIÓN LOCAL}

CAAMAÑO DOMÍNGUEZ, llama la atención sobre el que denomina curioso origen de la naturaleza bifronte del régimen local o, en sus palabras, que el Tribunal Constitucional atribuyó a la autonomía de municipios y provincias, ya que la STC 84/1982 no resolvía un recurso que impugnase un precepto que fuese básico frente a la competencia legislativa autonómica del 148.1.2. ${ }^{\mathrm{a}}$ Por tanto, se servía nuestro alto intérprete del «régimen bifronte» para despejar cualquier duda concerniente a la doble y simultánea subordinación (estatal y autonómica) y justificar una intervención estatal más allá de lo estrictamente básico con arreglo al art. 149.1.1827. Así, con ello, considera el profesor y exministro Francisco CAAMAÑO que el verdadero fondo de la Sentencia 84/1982 es aclarar los límites de las competencias legislativas del Estado y de las Comunidades Autónomas sobre la materia, concediéndose además al legislador estatal una etiqueta de garante de la autonomía local frente a cualquier posible agresión del legislador autonómico y, dando por supuesto, que las vulneraciones de la Autonomía local constitucionalmente garantizada solo llegarán de las Comunidades Autónomas ${ }^{28}$.

Así pues, al usar la expresión «régimen bifronte» nos encontramos, además, ante un modo de relación de tres ordenamientos, uno de ellos el de las Corporaciones Locales derivado, con los dos restantes, del Estado uno y autonómico el otro, que están conectados entre sí de manera tal que no solo vincula a las Comunidades Autónomas

dan hacerse de las propias del intérprete, se establece el punto de apoyo para la atribución al Estado de competencia exclusiva para dictar las bases del régimen local. Y, como se ha indicado, el epígrafe bajo el que se desarrolla el capítulo II del Título VIII «De la Administración local» permite el encaje adecuado en la expresión régimen jurídico de las Administraciones públicas del 149.1.18. ${ }^{\circ}$, que confiere al Estado la competencia exclusiva sobre la materia en cuestión. Por su parte, la ya mencionada STC 32/1981 afirmó, en relación al régimen local, ya sin dejar lugar a dudas que «[...] la garantía constitucional es de carácter general y configuradora de un modelo de Estado, y ello conduce como consecuencia obligada a entender que corresponde al mismo la fijación de los criterios o principios básicos en materia de organización y competencia de general aplicación en todo el Estado».

${ }^{27}$ CAAMAÑO DOMÍNGUEZ, F., «Autonomía local y Constitución: Dos propuestas para otro viaje por el callejón del gato», REDC, núm. 70, 2004. Pág. 8.

${ }^{28}$ Circunstancia, esta última, no exenta de ironía; máxime a la vista de la reforma del régimen local operada por la Ley 27/2013, de 27 de diciembre, de racionalización y sostenibilidad de la Administración local. Dicha reforma ha sido entendida por varios miles de municipios en todo el Estado como una «clara vulneración de la Autonomía local», habiéndose interpuesto ante el Tribunal Constitucional el correspondiente Conflicto en defensa de la Autonomía local, actualmente pendiente de resolución. 
con las Corporaciones locales, sino que, a su vez y para hacer realidad el principio de autonomía ${ }^{29}$, también liga a estas últimas con el Estado. Y este modo de relación es así dado que, como se señalaba más arriba, tanto Estado como Comunidades Autónomas disponen de un poder limitado (en función de su alcance competencial) sobre las Entidades locales. Las CC.AA. no podrán, vista la STC 84/1982, reservarse para sí la competencia exclusiva sobre régimen local evitando, por tanto, que aspiren a considerarlo en términos de la propia Sentencia como un asunto «intracomunitario». Y el Estado quedará encargado de aprobar la legislación básica en materia de régimen local, esto es regulación básica de la organización de la Administración local ${ }^{30}$ (que podrá completar y adaptar a cada realidad concreta el legislador autonómico, con competencias en la materia, al amparo del artículo 148.1.2. a de la Norma Fundamental), así como de garantizar un espacio de no intervención de las Comunidades Autónomas sobre la Autonomía local ${ }^{31}$.

En todo caso, conviene señalar que las entidades locales y, de modo más llamativo, el municipio con su fundamental carácter democrático termina siendo doblemente dependiente en lo que a la regulación de su régimen se refiere, si bien, esa dependencia deberá dejar el ámbito necesario, en relación a la determinación de los intereses locales, para facilitar que la autonomía local, constitucionalmente garantizada, logre el alcance y contenido que le da sentido ${ }^{32}$.

Y habiéndose introducido la garantía de la autonomía de los entes locales, bien es cierto que en relación a cualquier exceso de las Comu-

${ }^{29}$ Así lo afirma Francisco SOSA WAGNER, ya que en sus palabras «el principio de autonomía se hace realidad y, como poder subordinado, alcanza su verdadero sentido cuando se integra en el todo, es decir, en la unidad que la Constitución Española postula como propia de la organización de los poderes territoriales por ella diseñados». Los Principios... op. cit., pág. 165.

${ }^{30}$ Regulación básica de la organización de todas las administraciones públicas, es la definición que el Tribunal Constitucional dio de la expresión «régimen jurídico» en su Sentencia 76/1983, de 5 de agosto.

${ }^{31}$ Así lo afirma Francisco CAAMAÑO DOMÍNGUEZ en su ponencia «Autonomía Local y Principio de Subsidiariedad», donde apoyándose en un análisis jurisprudencial de Francisco VELASCO CABALLERO concluye que «Lo básico, como común denominador normativo del régimen jurídico de todos los entes locales en todo el territorio del Estado, es la expresión positivizada de la autonomía local que, por esta razón, es concebida como una realidad uniforme configurada por el legislador estatal y que actúa a modo de núcleo jurídico de resistencia frente a las eventuales injerencias de la legislación autonómica. Estas, y no otras, son las razones de fondo que han marcado la evolución de la jurisprudencia constitucional y, a veces, en recíproco auxilio, la acción normativa del legislador básico estatal».

${ }^{32}$ GARCÍA ROCA, J. El concepto actual de autonomía local... en LÓPEZ GUERRA, L. Estudios de Derecho Constitucional. Homenaje al Profesor... op. cit., pág. 647.

(C) UNED. Revista de Derecho UNED, núm. 18, 2016 
nidades Autónomas, no cabe estudio de la Autonomía local que no incluya su consideración como una "garantía institucional» por la jurisprudencia constitucional, así como su contestación por parte de determinada corriente doctrinal.

\section{LA TÉCNICA DE LA GARANTÍA INSTITUCIONAL EN LA JURISPRUDENCIA DEL TRIBUNAL CONSTITUCIONAL}

La «garantía institucional» es una técnica de protección que tiene su origen en el Derecho alemán ${ }^{33}$ y fue introducida por la doctrina administrativista ${ }^{34}$ con una muy rápida aceptación y aplicación por parte del Tribunal Constitucional que, en su Sentencia 32/1981, de 28 de Julio, hizo uso de ella en la salvaguarda que este instrumento ofrece para la Autonomía local ${ }^{35}$.

Numerosas son las Sentencias ${ }^{36}$ que han asentado la doctrina de la garantía institucional en nuestra Jurisprudencia configurándola como una técnica para garantizar y asegurar la existencia de unas instituciones locales, que serán consideradas como elementos arquitecturales indispensables del orden constitucional. Tal y como se avanzaba más

${ }^{33}$ La técnica de la "garantía institucional» se desarrolla en Alemania por inspiración de Carl SCHMITT y nace con el objeto de establecer un nivel, o tratamiento mínimo, que debe atribuirse por el Derecho positivo a cada institución, todo ello, con el objetivo de preservarla de cualquier agresión o degradación a que pueda llevarla la correspondiente regulación. El propio SCHMITT, en su Teoría de la Constitución, la definió como un reducto en el que es posible ciertamente la acción del legislador, pero éste carece de una facultad de disposición total e inmediata.

${ }^{34}$ Fueron los primeros en introducir esta técnica en el Derecho español PAREJO ALFONSO L., Garantía institucional y autonomías locales, IEAL, Madrid, 1981; EMBID IRUJO, A., Autonomía municipal y Constitución: aproximación al concepto y significado de la declaración constitucional de autonomía municipal. REDA n. ${ }^{\circ} 30,1981$ y MARTÍN MATEO, R., La garantía constitucional de las autonomías locales, REVL N. ${ }^{\circ}$ 208, 1980. Todos ellos acabarían ocupando Cátedras de Derecho Administrativo.

${ }^{35}$ A este respecto, es digna de mención la consideración de GARCÍA ROCA cuando, afirma que «uno de los grandes problemas del Derecho Español y, en particular, de la Teoría del Estado española ha sido -a juicio de muchos- un exceso de traducciones de textos alemanes y franceses en detrimento de una verdadera reflexión propia» y señala cómo en Alemania la autonomía local es considerada como un derecho asimilable a los derechos fundamentales, mientras que en España no es considerado como tal. Y pone de manifiesto las complicaciones que resultan cuando por seguir otras teorizaciones ajenas se incurre en «papanatismos»-llega a decir- como en el caso de la autonomía universitaria y su consideración como derecho fundamental. GARCÍA ROCA, J., El concepto actual de autonomía local según el bloque de constitucionalidad» en Estudios de Derecho Constitucional. Homenaje al Profesor... op. cit. Págs. 657-658

${ }^{36}$ Sentencias 32/1981, 27/1987, 213/1988, 213/1989 
arriba su finalidad es eminentemente protectora de la institución frente a cualquier posible agresión del legislador ordinario, siendo por tanto un instrumento defensivo frente a la actividad legislativa, así la STC 109/98, en su fundamento jurídico segundo establecerá que «la garantía institucional de la autonomía local no asegura un contenido concreto ni un determinado ámbito competencial sino la preservación de una institución en términos recognoscibles para la imagen que de la misma tiene la conciencia social en cada tiempo y lugar, de suerte que sólo podrá reputarse desconocida dicha garantía cuando la institución es limitada de tal modo que se la priva prácticamente de sus posibilidades de existencia real como institución para convertirse en un simple nombre».

\section{LA DOCTRINA ANTE LA TÉCNICA DE LA GARANTÍA INSTITUCIONAL}

Siguiendo a PAREJO ALFONSO, máximo exponente de la doctrina favorable a esta técnica, en los artículos 137, 140, 141 y 142 de la Constitución Española se establece una garantía institucional de la autonomía local, y por ello las entidades locales previstas en ella son titulares de un derecho a la autonomía constitucionalmente garantizado. Por otra parte, y tal y como establece la jurisprudencia, el orden jurídico-político contenido en nuestra norma fundamental asegura la existencia de determinadas instituciones que son consideradas componentes esenciales y, por tanto, deben ser preservadas ${ }^{37}$ para el cumplimiento de los Principios Generales de la organización territorial del Estado, recogidos en nuestra Constitución. Por tanto, el derecho a la autonomía (para la gestión de sus intereses) de los entes locales quedará asegurado y protegido ${ }^{38}$ ya que así lo prevé nuestra Carta Magna, si bien su configuración institucional concreta quedará en manos del legislador ordinario, con la capacidad limitada por la propia garantía

${ }^{37}$ Y la preservación, tal y como establece la STC 32/1981, ha de serlo en los términos que permitan reconocer la imagen que de la institución tenga la conciencia social de cada tiempo y lugar.

${ }^{38}$ Hace especial hincapié Luciano PAREJO, en ese carácter defensivo y protector, cuando insiste en que «El carácter defensivo, o mejor protector, de la 'garantía' es, pues, consustancial a ésta. Surge precisamente, y al igual que el 'contenido' esencial, de los derechos fundamentales (que tienen el mismo origen e idéntica funcionalidad en campo distinto) para limitar la acción de configuración del legislador ordinario, de modo que está articulada para operar 'frente a' y 'contra' ésta.» PAREJO ALFONSO, L., La Garantía Institucional: crítica... op. cit., pág. 57. 
constitucional de la institución ${ }^{39}$. De modo que, en palabras del profesor, no encontraremos un diseño constitucional directo, mínimamente detallado, del régimen local, y por decisión constitucional será el legislador ordinario el llamado a configurar dicho régimen. Así pues, esa garantía no alcanzará a precisar cual será el conjunto de intereses y competencias de los entes locales en cuestión, ya que esa tarea corresponderá al legislador (estatal y/o autonómico) ${ }^{40}$.

En definitiva -asegura $\mathrm{PAREJO}^{41}$ - la autonomía local que goza constitucionalmente de una garantía institucional tiene un contenido mínimo que el legislador debe respetar. Un contenido mínimo que limita al derecho de la comunidad local a participar, a través de órganos propios, en la gestión de los asuntos que les afectan, debiendo gozar por tanto de las potestades necesarias. Más allá de ese contenido mínimo, la autonomía local es un concepto de contenido y configuración legal. Ciertamente con el límite, que señalábamos más arriba, de la propia garantía institucional que no impide al legislador la ampliación más allá del contenido directamente garantizado por la norma fundamental, del ámbito de la autonomía local. Por otra parte añade, en relación con el requisito material fundamental de la autonomía que trataremos más adelante, la autonomía de los entes locales está, por tanto, estrechamente ligada a su suficiencia financiera, por cuanto exige la plena disposición de medios financieros para poder ejercer sin condicionamientos indebidos y en toda su extensión, las funciones que legalmente les han sido encomendadas [...] es decir para posibilitar y garantizar, en definitiva, el ejercicio de la autonomía constitucionalmente reconocida ${ }^{42}$.

${ }^{39}$ En efecto, "esa garantía institucional supone 'el derecho de la comunidad local a participar a través de órganos propios en el gobierno y administración de cuantos asuntos le atañan, graduándose la intensidad de esta participación en función de la relación existente entre los intereses locales y supralocales dentro de tales asuntos o materias. Para el ejercicio de esa participación en el gobierno y administración de cuanto les atañe, los órganos representativos de la comunidad local han de estar dotados de las potestades sin las que ninguna actuación autonómica es posible'. Más allá de este límite de contenido mínimo que protege la garantía institucional, la autonomía local es un concepto jurídico de contenido legal, que permite, por tanto configuraciones legales diversas, válidas en cuanto respeten aquella garantía institucional. Por tanto en relación con el juicio de constitucionalidad sólo cabe comprobar si el legislador ha respetado esta garantía institucional.» STC 170/1989.

${ }^{40}$ PAREJO ALFONSO, L., La Garantía Institucional: crítica... op. cit., pág. 57.

${ }^{41}$ PAREJO ALFONSO, L., La autonomía local en la Constitución, en MUÑOZ MACHADO, S. (dir.), Tratado de Derecho Municipal, tomo I, 2. ${ }^{a}$ ed., Civitas, Madrid, 2003. Págs. 45-48.

${ }^{42}$ Muy cuidadoso y con el rigor que le caracteriza, no utiliza aquí PAREJO la expresión tantas veces repetida de «Autonomía financiera de los entes territoriales» (de 
Por todo ello, propone PAREJO lo que denomina el triple efecto básico de la garantía institucional de la autonomía local, a saber: en primer lugar la no constitucionalidad de toda propuesta de organización territorial del Estado que no contemple municipios y provincias, en segundo lugar, la necesariedad de que la definición del estatuto de nuestros entes locales se lleve a cabo mediante Ley formal, y, por último, la posibilidad constitucional de supresión o eliminación o modificación de cualquier municipio, provincia o isla, siempre que sea puntual o individual y no pueda considerarse como una supresión institucional de carácter general.

En una posición notablemente crítica encontramos al profesor GARCÍA FERNÁNDEZ, con quien coincidimos cuando afirma que la noción de garantía institucional es un claro ejemplo de cómo se han abordado, desde posiciones poco prácticas, los principios constitucionales de la administración local. Además, considera que dicha técnica, a pesar de calificarla como una «elaboración brillante», en España ha dado lugar a una "concepción total y cerradamente radical de las Entidades locales como entes administrativos ajenos a lo político» ${ }^{43}$. Y esta reflexión nos parece de gran relevancia al ponerla en relación con la delimitación ya señalada en el apartado correspondiente al sistema político franquista, pues la pretensión de despojar del fundamental carácter político encierra, como consecuencia directa, la consideración del Derecho local exclusivamente como parte del Derecho administrativo, mientras que «la atribución de naturaleza política al órgano local inserto en la estructura de poder del Estado con carácter democrático-electivo más o menos autónomo (lo que siempre tiene reflejo en la Constitución)» hace que su regulación se inserte en el Derecho Constitucional ${ }^{44}$.

Otro sector doctrinal, en el que destaca de modo significativo el ya mencionado Joaquín GARCÍA MORILLO, ha aceptado la utilidad que ha prestado la técnica de la garantía institucional para impedir cualquier vaciamiento de contenido de nuestras entidades locales por parte del legislador (básicamente autonómico), reconociendo el carácter defensivo de este instrumento. Pero, simultáneamente, ha puesto de manifiesto la incapacidad de esta técnica para ir más allá de la limitación al legislador para garantizar la existencia de las instituciones lo-

la que, en puridad, carecen municipios y provincias) aplicándola a los entes locales sino, con toda corrección, suficiencia financiera.

${ }^{43}$ GARCÍA FERNÁNDEZ, J., «Derecho Constitucional y Entidades locales. Sistema...» Op. cit., pág. 206.

${ }^{44}$ Op. cit., pág. 217. 
cales $^{45}$. En esos términos cabría la posibilidad de contemplar el supuesto de la autonomía universitaria, si no se hubiera ubicado en la sección primera del capítulo II del Título Primero ${ }^{46}$. Pero en el caso de la autonomía de los entes locales, nuestra norma fundamental no se limita a mencionar la figura para garantizarla -señalaba GARCÍA MORILLO- la rodea de otras muchas características que, además, ocupan un lugar importante entre nuestros principios constitucionales. Si se garantiza la pervivencia de nuestros entes locales no es solamente porque se mencionen en la Constitución, es que además los configura como entes básicos de la división territorial del Estado. Y, por si fuera poco, se les establecen las características fundamentales de su organización recogiéndose, para el caso de los municipios, la aplicación del principio democrático para la elección de sus concejales mediante sufragio universal, libre, directo y secreto.

Concluía el profesor GARCÍA MORILLO que «la Constitución va más allá del mero establecimiento de una garantía institucional, no sólo protege los órganos locales, sino que-sobre todo en lo que a los municipios se refiere- regula sus características básicas, reitera su carácter autónomo y los inviste de uno de los valores superiores del ordenamiento constitucional, el de ser expresiones del pluralismo político y manifestaciones del principio democrático» ${ }^{47}$. Por todo ello, considera nuestro autor que se pone de manifiesto que la técnica de la garantía institucional se muestra incapaz o, al menos, insuficiente para establecer y esclarecer la regulación constitucional de la autonomía local.

Propone una garantía constitucional de la autonomía local que consistiría en la consideración de nuestros entes locales como unos órganos que la Constitución quiere que existan, pero que existan con

${ }^{45}$ Por otra parte, el profesor GARCÍA MORILLO, pondrá de manifiesto, y así lo reconoce el propio Luciano PAREJO, los aspectos «críticos» de la garantía institucional de la autonomía local; en concreto la técnica del «núcleo» indisponible para el legislador (equivalente «objetivo» del «contenido esencial» de los derechos fundamentales) -por tratarse, además de un concepto jurídico indeterminado que, aún necesitado de concreción, no puede negársele su utilidad-, junto al ya señalado carácter puramente defensivo. Si bien, el reputado administrativista, aceptando lo fundado de la crítica, negará que sean decisivas para justificar el abandono de la garantía institucional. PAREJO ALFONSO, L., La Garantía Institucional: crítica... op. cit., pág. 53.

${ }^{46}$ La ubicación de la autonomía de las universidades en el artículo 27 (dentro de la sección dedicada a los Derechos fundamentales y las libertades públicas) de nuestra Constitución será, junto con la adopción de según que técnicas del derecho alemán, el argumento para su consideración y catalogación como derecho fundamental por el Tribunal Constitucional.

${ }^{47}$ GARCIA MORILLO, J., La Configuración constitucional... Op. cit., pág. 35. 
una finalidad clara (organización territorial del Estado), quiere que existan de una manera y con una organización determinada (siendo expresión del pluralismo político y manifestación del principio democrático) y, además, quiere también que existan para el cumplimiento de una serie de funciones (que deberán establecerse por el legislador $)^{48}$. De modo que frente a la garantía institucional como mecanismo de defensa con respecto al legislador, se va a elaborar una propuesta de garantía constitucional que sería algo más que un límite al poder legislativo, sería un fundamento sobre el que apoyar una interpretación de la autonomía local no solamente protectora sino dotada de parámetros configuradores de instituciones y cuya consecuencia es la exigencia de un contenido indispensable para el despliegue de las funciones que la institución tiene constitucionalmente asignadas ${ }^{49}$.

La garantía constitucional podría ser el fundamento apropiado para una exigencia constitucional de dotación de contenido a nuestros entes locales, como se ha puesto de manifiesto más arriba, debilidad fundamental de la técnica de garantía institucional. Porque la regulación constitucional de las instituciones tiene un propósito finalista -señalaba GARCÍA MORILLO- y una función configuradora: se desea que las instituciones sean de una manera, y no de otra. Y apunta alguna casuística jurisprudencial como la STC 170/1989, sobre la Ley madrileña de disciplina urbanística, en la que se afirma que «... los acuerdos referentes a ordenación, gestión, ejecución y disciplina urbanistica y más precisamente la autorización para la edificación y otros usos del suelo que, por otra parte, constituye una competencia característica de los Municipios...». Y resulta así que, a modo de ejemplo, podrá hablarse de competencias características de los municipios ${ }^{50}$ que configurarían el contenido constitucional mí-

${ }^{48}$ El mismo Luciano PAREJO vendrá a reconocer que «la garantía institucional se limita a 'preservar' el autogobierno de las entidades locales y que por ello, y en el terreno de las tareas-competencias, sólo logra operar ex post, es decir, a partir de la comprobación efectiva de que tras una medida legislativa reductora de competencias no resta contenido material suficiente para otorgar el soporte y el espacio mínimos precisos para la actuación de aquel autogobierno». PAREJO ALFONSO, L., La Garantía Institucional: crítica... Op. cit., pág. 58.

${ }^{49}$ A estos argumentos se sumaría lo previsto por el artículo 3.1 de la Carta Europea de la Autonomía Local donde se establece que autonomía local es «el derecho y la capacidad efectiva de las entidades locales de ordenar y gestionar una parte importante de los asuntos públicos en el marco de la ley» haciendo especial hincapié en que se habla de una parte importante y, por tanto, de un contenido necesario para que las instituciones locales puedan cumplir la función que la Constitución les asigna y no exclusivamente el mínimo imprescindible para que sobrevivan.

${ }^{50} \mathrm{~A}$ este respecto, y concretamente en lo relativo a las competencias locales, el propio Luciano PAREJO, en su defensa de la técnica de la garantía institucional, ven- 
nimo de la Autonomía local y, siguiendo ese precedente, podría adoptarse un nuevo criterio jurisprudencial que acogiese esta propuesta de garantía constitucional ${ }^{51}$.

Otros autores han optado por proponer una reinterpretación de la técnica de la garantía institucional "de un modo más moderno» afirma literalmente REQUEJO RODRÍGUEZ y así no tener que recurrir a la creación una nueva categoría (garantía constitucional frente a garantía institucional $)^{52}$. Pero, en todo caso, en lo que resultan realmente coincidentes es la necesidad de que se proceda a revisar la doctrina de la garantía institucional, tal y como actualmente la tiene concebida nuestro Tribunal Constitucional.

Por su parte, GARCÍA ROCA insiste en la posición de GARCÍA MORILLO justificando que el Tribunal Constitucional adoptó la técnica de la garantía institucional en un momento en el que aún no existía un bloque de la constitucionalidad local, para lo que se sirvió de dicha técnica con objeto de preservar la existencia de la provincia. Pero en esa limitación defensiva se manifestó, simultáneamente, su incapacidad para configurar el contenido de la autonomía local. Por otro lado, la técnica de la garantía institucional exigiría la preexistencia de unas instituciones locales ya perfectamente definidas y configuradas en el momento constituyente y, señala el autor, la autonomía local de origen preconstitucional no es un concepto que pudiera recibirse pacíficamente como institución por la Constitución de 1978, sea cual fuere la silente voluntad de los constituyentes. Añade, sumándose a quienes ponen de manifiesto las limitaciones a la hora de ejercer la función configuradora, que esta técnica de la garantía institucional no

drá a reconocer que "la garantía institucional no constituye un límite claro y definitivo a las operaciones legislativas de asignación y reasignación de competencias [...] y mucho menos supone, por sí sola, criterio y directriz positivas para la verificación de éstas [...] pero ello no tanto por una deficiencia o incapacidad propia o una obsolescencia sobrevenida, cuanto por el dato elemental de circunscribir su función constitucional precisamente a la preservación de la opción del legislador constituyente por el autogobierno local, es decir, la defensa de dicha opción frente al legislador ordinario» PAREJO ALFONSO, L., La Garantía Institucional: crítica... Op. cit., pág. 58.

${ }^{51} \mathrm{Y}$ ahora se entenderá con todas sus implicaciones la definición que nos formulaba GARCÍA MORILLO, en su obra ya citada, de la garantía constitucional «una predisposición o criterio interpretativo cuyo efecto sería la interpretación del contenido de la autonomía local no en los términos protectores que inspiran la noción de contenido esencial de los derechos fundamentales, esencialmente protectores, sino en razón de parámetros configuradores de instituciones y cuya consecuencia es la exigencia de un contenido indispensable para el despliegue de las funciones que la institución tiene constitucionalmente asignada».

52 REQUEJO RODRÍGUEZ, P. en «El nuevo diseño de las competencias locales», en Cuadernos de Derecho Local n. ${ }^{\circ}$ 13, Febrero de 2007. Fundación Democracia y Gobierno Local. pág 25. 
habilita, ni siquiera permite, para poder definir el interés local, ni cuáles podrían ser los ámbitos de actuación local, ni las competencias locales, ni cómo ha de articularse el principio de suficiencia de recursos de las entidades locales ${ }^{53}$. En resumen, considera que la garantía institucional es una técnica totalmente limitada y, por tanto, no resulta apropiada para definir de modo positivo, útil y efectivo la autonomía local.

Definitivamente, debemos añadir, el Tribunal Constitucional, a través de la doctrina de la garantía institucional, logró preservar la existencia de la Provincia -siendo absolutamente eficaz para este cometido- pero, simultáneamente, incorporó una técnica muy limitada, cuando no incapaz, para la configuración del contenido de la autonomía de los entes locales que, para el autor, sería el verdadero problema a resolver.

Por último, propone GARCÍA ROCA, una garantía constitucional de la autonomía local se asentaría sobre la función de configuración constitucional que, dada la consideración de nuestra Carta Magna como una Constitución abierta en materia de descentralización territorial, se llevaría a cabo por la acción del legislador (estatal y autonómico, con la Ley de Bases de Régimen Local y los Estatutos de Autonomía) a través de la determinación de lo que él denomina un «bloque de la constitucionalidad local ${ }^{54}$. En definitiva, se trataría de entender que la Constitución lo que establece es un bosquejo de lo que deberán ser los entes locales, señalando su esencia y características principales permitiéndose, a su vez, a la ley su expansión, desarrollo y amplificación.

Francisco CAAMAÑO y Mayte SALVADOR verán una ventaja añadida a la sustitución de la técnica de garantía institucional por la garantía constitucional en positivo y es que permitirá escapar a la singular circunstancia de que sea el propio legislador el encargado de definir el ámbito de intereses propios de las entidades garantizadas y, además, tal definición sirva para enjuiciar la propia constitucionali-

${ }^{53}$ GARCÍA ROCA, J., El concepto actual de autonomía local... en LÓPEZ GUERRA, L. Estudios de Derecho Constitucional. Homenaje al Profesor... Op. cit., págs. 658 y ss.

${ }^{54}$ Afirma literalmente que «La institución -la autonomía local-no está fuera de la Ley Fundamental y en las libres manos del legislador salvo un remoto espacio nuclear compuesto por la defensa de su existencia, alguna facultad y poco más. Esto es así, aunque no haya listas constitucionales expresas de competencias y esa pormenorización del interés local deba encontrarse en la Ley de Bases de Régimen Local y -por qué no también-en los Estatutos de Autonomía y sus sucesivas reformas». GARCÍA ROCA, J. El concepto actual de autonomía local... en LÓPEZ GUERRA, L. Estudios de Derecho Constitucional. Homenaje al Profesor... op. cit. pág. 655 y ss. 
dad de la actuación legislativa. Se evitaría, así, que sea el propio legislador (estatal) el «garante» de la autonomía local frente a las agresiones del legislador (que en apariencia será previsiblemente autonómico, pero -como el transcurso del tiempo pondrá de manifiesto- podrá ser también ser estatal).

Por su parte VELASCO CABALLERO, denunciará lo que denomina la insuficiencia explicativa del concepto de "garantía institucional» como la de su corrección positiva en el concepto de "garantía constitucional», y propondrá la explicación de la autonomía local como «poder constitucional de progresiva elevación estatutaria y legal» sosteniendo que según determinada jurisprudencia constitucional ${ }^{55}$ nuestra autonomía presenta rasgos propios de la categoría jurídica de «principio» ${ }^{56}$.

En la misma línea doctrinal vamos a encontrar al profesor GARCÍA FERNÁNDEZ quien señala que, al calificar el principio de Autonomía local como uno de los fundamentos de la constitucionalización del Derecho local, carece de sentido la polémica Garantía institucional-Garantía constitucional, pues dicho principio, al igual que la garantía de un ámbito de intereses locales propios, se encuentran claramente constitucionalizados y el ámbito atribuido a la ley ha de ser el de ordenar conforme a técnicas jurídicas el alcance de los intereses locales fijando los procedimientos para su gestión de acuerdo con nuestro principio. Señala, asimismo que «Por eso, una vez rebasada la noción de garantía institucional no tiene sentido sustituir un adjetivo por otro. Como instituto fijado en la Constitución, la autonomía local tiene la misma garantía que el sufragio universal, la iniciativa legislativa del Gobierno o la Regencia y no se nos ocurre hablar de la garantía constitucional de estas instituciones. En definitiva, a mi entender, la expresión garantía constitucional sólo quiere decir que la autonomía local ha de tener una garantía jurisdiccional en sede del Tribunal Constitucional, lo cual iba de suyo pues, como decía Virga, toda violación de la Constitución constituye un ilícito contra el que el ordenamiento debe reaccionar con las sanciones adecuadas». Concluye el autor, por tanto, que "Por eso cuando la Constitución afirma en su artículo 140 que la Constitución garantiza la autonomía de los municipios' está introdu-

55 Se refiere a las SSTC 40/1998, 204/2002, y a las SSTC 132/2001, 233/1999, Sentencias en materia de urbanismo y régimen sancionador, respectivamente, en las que la autonomía local constitucionalmente garantizada ha sido utilizada por el Tribunal Constitucional como principio para la hermenéutica constitucional tendente a lograr la máxima satisfacción que permite la Constitución de la autonomía local. VELASCO CABALLERO, F., "Autonomía municipal» Ponencia en el II Congreso... Op. cit. pág. 29 y ss.

${ }_{56}$ Op. cit. pág. 30. 
ciendo, más que una especial garantía constitucional para el principio de autonomía, una afirmación de pleno contenido histórico para remachar que el texto constitucional se inclina del lado de las Constituciones progresistas españolas que reconocían la posición política autónoma del Municipio». En cualquier caso, reconoce a los autores que integran la doctrina defensora de la Garantía constitucional su contribución para "escapar» "del campo 'institucionalista-schmittiano' en el que alguna doctrina y el propio Tribunal Constitucional encerraron el principio de autonomía local con lo que vinieron a desconstitucionalizarlo» ${ }^{57}$.

Mayte SALVADOR ${ }^{58}$, recogiendo nuevas propuestas del Anuario del gobierno local 2001, apunta, asimismo, lo que se ha dado en llamar la proyección exterior de la autonomía local que pretende que, más allá de las facultades de gestión sobre los asuntos propios, las entidades locales gocen de la posibilidad de intervención en su definición en vía legislativa y defenderlos estando presentes en otros niveles de gobierno (bien sea en sede parlamentaria o en otras sedes políticas).

\section{LA JURISPRUDENCIA DEL TRIBUNAL CONSTITUCIONAL Y LA DOCTRINA ANTE LA AUTONOMÍA LOCAL: CONCLUSIONES}

En resumen, y como conclusión, lejos de ser un capítulo cerrado, la delimitación y configuración de la Autonomía de los entes locales en España, a la luz de nuestra vigente Constitución de 1978, es una tarea en la que aún pueden tener mucho que decir la Jurisprudencia del Tribunal Constitucional y la Doctrina, siempre y cuando -eso sí- se acepte, fundamentalmente por parte del más alto intérprete, la necesidad de ir más allá de la consideración defensiva y poco extensiva que se ha efectuado hasta la fecha ${ }^{59}$. Todo ello, a la vista de las nuevas propues-

${ }^{57}$ GARCÍA FERNÁNDEZ, J., «Derecho constitucional y entidades locales. Sistema...». Op. cit., págs. 237-238.

${ }_{58}$ SALVADOR CRESPO, M., La autonomía provincial..., op. cit., pág. 77.

${ }^{59}$ En la misma línea, demandando al Tribunal Constitucional una interpretación más completa, ampliada o extensiva de la Administración local, encontramos -desde sus posiciones ya señaladas- al Profesor Luciano PAREJO cuando concluye que "En definitiva, pues, no puede coincidirse ni en la obsolescencia de la garantía institucional, ni en la procedencia de su sustitución por la llamada garantía constitucional, pero sí, sin duda, convenirse en la insuficiencia de la primera para-desde sí misma y desligada del restante contexto constitucional-asegurar la integridad y el desarrollo adecuado de la posición y la función constitucionales de la Administración local como pieza del Estado, y la consecuente necesidad-expresada en la segunda-de una interpretación de la norma fundamental que decante el completo marco constitucional (comprensivo de la garantía institucional) al que debe ajustarse, en el que debe moverse y que debe inspirar la total acción del legislador ordinario que afecte a la

(C) UNED. Revista de Derecho UNED, núm. 18, 2016 
tas hermenéuticas mucho más próximas a la orientación que el concepto Autonomía local parece que tomará en el futuro si se avanza en el desarrollo de la Carta Europea de la Autonomía Local.

Para ir finalizando, nos hacemos eco de las palabras del profesor Óscar ALZAGA ${ }^{60}$ cuando afirma que la Constitución, como Norma Fundamental, al incorporar valores y principios, así como mandatos al legislador, hace que la interpretación constitucional se diferencie notablemente de la que se lleva a cabo de otras normas jurídicas y, singularmente, en relación al aspecto temporal. Pues, dicha interpretación, deberá permitir la actualización constitucional.

Y terminamos añadiendo que, al menos por el momento, la mencionada actualización difícilmente va a poder ser llevada a cabo mientras el Tribunal Constitucional no varíe la conceptuación que, a través de su primera jurisprudencia, hizo de la Autonomía de los entes locales que, como se ha puesto de manifiesto, pareció obedecer a finalidades distintas de la necesaria configuración de nuestro principio de la organización territorial de Estado. Nuestro más alto intérprete y, por supuesto, también el legislador básico tienen a su alcance la posibilidad de promover una doctrina renovada de la garantía constitucional más acorde con el papel de las entidades $\operatorname{locales}^{61}$, una vez superada una primera etapa definidora de la Autonomía de nacionalidades y regiones. Hemos visto que la consideración de la Autonomía Local en la jurisprudencia del Tribunal Constitucional y en la doctrina ha venido, en buena medida, condicionada por la realidad de la nueva construcción del Estado de las Autonomías en la España de la Constitución de 1978. Y ha llegado, quizás, el momento en que, de verdad, sea necesario el desarrollo de un segundo proceso descentralizador, en este caso hacia las entidades locales, muy especialmente, hacia los Municipios, dándoles una consideración que vaya más allá de meras colaboradoras del Estado y las Comunidades Autónomas. Coincidimos plenamente con GOIG MARTÍNEZ y NÚÑEZ MARTÍNEZ ${ }^{62}$,

Administración local». PAREJO ALFONSO, L., La Garantía Institucional: crítica... op. cit., pág. 60.

${ }^{60}$ ALZAGA VILLAMIL, O., GUTIÉRREZ GUTIÉRREZ, I. y RODRÍGEZ ZAPATA, J., Derecho Político Español según la Constitución de 1978.(Vol. I) Constitución y fuentes del Derecho, Editorial Universitaria Ramón Areces, Madrid, 2001, págs. 76 y 77.

${ }^{61}$ No caemos en la ingenuidad de desconocer la tremenda dificultad que dicha propuesta entraña. Ahora bien, si responde a la realidad jurídico-política actual, no vemos la imposibilidad para que el órgano fundamental, que llamamos Tribunal Constitucional, pueda participar decisivamente en la concreción de una voluntad estatal que, formal y debidamente, la refleje.

${ }^{62}$ GOIG MARTÍNEZ, J. M., NÚÑEZ RIVERO, C., NÚÑEZ MARTÍNEZ, M., La Constitución Española en la Jurisprudencia... op. cit., pág. 308. 
cuando afirman -teniendo como punto de partida el principio de subsidiariedad- que las administraciones estatal y autonómica únicamente deberían asumir aquellas competencias que no sean posibles en la Administración Local. Y esta tarea solamente podrá llevarse a cabo si nuestro más alto intérprete, acepta jugar un papel fundamental que pasará, necesariamente, por la «revisión» de su enfoque actual de la Autonomía Local. En caso contrario, y esa parece ser la voluntad del legislador a la vista de la Ley de racionalización y sostenibilidad de la Administración Local, la alternativa habrá de llegar por la procelosa vía de la reforma Constitucional.

Entre tanto, por lo sencillo e ingenioso, merece una cierta atención la propuesta de Francisco CACHARRO, en la que siguiendo a Luciano PAREJO cuando afirma que la Carta Europea de la Autonomía Local codifica la imagen europea de la Autonomía local, sugiere que nuestro Tribunal Constitucional, sin salirse de su doctrina, adopte y se sirva de la «imagen» de la Autonomía local en la Carta Europea (con su reconocimiento en el Preámbulo como contribución esencial en la construcción de una Europa basada en los principios de democracia y descentralización del poder, que señalábamos al principio de este apartado) para dar contenido a la recognoscibilidad de las instituciones locales por la conciencia social y, así, sin salirse de la técnica de la Garantía Institucional, se ampare una nueva consideración de la Autonomía local ${ }^{63}$.

${ }^{63}$ CACHARRO GOSENDE, F. Los medios de reacción de las entidades locales frente a posibles incumplimientos legislativos de la Carta Europea de la Autonomía Local en CAAMAÑO DOMÍNGUEZ, F. (coord..) La autonomía de los Entes en positivo. Serie claves del gobierno local, 1, Fundación Democracia y Gobierno Local, Madrid-Barcelona, 2003. Págs. 243-258. 
